\title{
Tenure, functional track and strategic leadership
}

\author{
Paper submitted to \\ International Journal of Educational Management
}

by

Dr Scott Eacott

\begin{abstract}
Author Bio
Scott Eacott is a lecturer at the University of Newcastle, Australia. His current research area is strategy in education and particular viewing leadership strategies through the work of the French sociologist Pierre Bourdieu. Scott teaches educational leadership courses at both the post-graduate and under-graduate levels in addition to supervising a number of doctoral students.
\end{abstract}

\section{Correspondence to:}

Dr Scott Eacott

School of Education

Faculty of Education and Arts

University of Newcastle

Callaghan NSW AUSTRALIA 2308

Ph: $\quad 61249217805$

Fax: $\quad 612449217887$

Email: Scott.Eacott@newcastle.edu.au 


\section{ABSTRACT}

Purpose: The purpose of this paper is to investigate whether the demographic variables of tenure and functional track have a moderating effect on the strategic leadership of school leaders.

Design/methodology/approach: Using a conceptual framework developed by the researcher, a static/cross-sectional questionnaire based study on a convenience sample of public primary school principals in NSW Australia, was used to collect data. Analysis included ANOVA and correlations.

Findings: Despite few statistically significant differences in the data set, there is evidence to suggest that based on the small sample size, the demographic variables of tenure and functional track have a moderating effect on the strategic leadership and management of public primary school principals.

Research limitations/implications: This study serves as little more than a scoping project. The small sample size limits the generalisability of the findings, however, the results do indicate that there is something to be made of the general thesis of the paper.

Practical implications: As education systems across the globe are faced with a crisis in filling school leadership positions with the mass retirement of the baby boomers, the potential implications of tenure and functional track on school leadership is of vital importance to all involved in schools.

Originality/value: This paper makes use of tenure and functional track in relation to strategic leadership, a combination rarely seen in the field. The very concept of functional track is original to the field and has the potential to uncover much needed insight into school leadership.

Keywords: strategy; strategic leadership and management; tenure; functional track; school leadership

\section{Research paper}




\section{Introduction}

There is a growing body of international evidence suggesting a shortage of highly qualified and experienced educational leaders. Examples cite anywhere between 40-90\% of current educational leaders retiring in the next five years. In this context, a simplistic characteristic of the educational leader to consider is his / her age, asking such questions as: Do younger leaders exhibit behaviors differently to older leaders? Is there an age range that appears to perform better? However, the conceptualization of the educational leader by age is limited, and in the contemporary higher education context with an increasing number of mature-aged students undertaking study, the correlation of age to performance may miss much of what is to offer in relation to career development. In this paper, the discussion is focused on the leader characteristics of tenure (as measured by time in years in their current substantive position) and functional track (a term used in the strategy literature, but rarely seen in education, referring to the time in years spent at different levels of the organizational hierarchy). To frame the discussion, the strategic role of the educational leader (Eacott, 2008b) is used. The underlying thesis of this paper is that both tenure and functional track have an affect on the strategic role of the educational leader.

\section{The conceptual framework}

The selection of strategy as a conceptual framework for the discussion represents a continued research agenda by the author (2004; 2006a; 2006b; 2007a; 2007b; 2007c; 2008a; 2008b; 2008c). The conceptualization of strategy for the purpose of this paper is that of an epistemological realist. Previously, following on from an analysis of the use of 
strategy in the educational leadership literature since 1980, I proposed a conceptual framework for strategy in education that consisted of five dimensions: envisioning; engaging; articulating; implementing; and monitoring. Envisioning requires a vision for the future but is built on critical reflection and dialogue. Engaging is about strategic conversations. These conversations build on critical reflection, establish purpose for actions and encourage a culture of reflection and dialogue on strategic matters and the future direction of the school. Involving as wide as group as possible provides richer source of data on the school to inform discussion and debates and if done well, gives others the feeling that their contribution is important, recognized and can make a difference. There are three inter-related levels within the articulating dimension: oral, written and structural. Oral articulation involves not only articulating the institutional vision/direction, but also bringing it to life through conversations and dialogue (Davies \& Davies, 2006). Written articulation involves distinguishing between daily operations and strategic operations and articulating in writing, a small set of deliverable objectives that the institution can achieve and focus efforts. Structural articulation requires the school to be aligned (e.g. curriculum teams or strategic priority teams) in a manner that is consistent with the strategic direction and integrated into all aspects of organizational life. Implementation is primarily concerned with how the school's strategy can be witnessed. Its central aspect is translating strategy into action, establishing frameworks and ensuring that they become actions. Building on from other features implementation requires that staff understand the school's strategy and maintain a commitment to enacting that strategy. Due to the iterative nature of strategy as a process, monitoring and evaluation are two crucial elements to effective implementation. The educational leader needs to be 
constantly asking themselves and others, Where are we now? Where to next? How will we get there? How will we know when we get there? There is a need for a transparent system of data collection to enable effective monitoring and predetermined points of evaluation. Pivotal to the success of this dimension of strategy is developing the analytical skills of others to ensure thorough evaluation.

Two demographic measures are used in this present work, tenure and functional track. The underlying assumption is that demographic characteristics of educational leaders make a difference. This is the central thesis of Upper Echelon Theory (Hambrick \& Mason, 1984) and the later revision to Strategic Management Theory (Finkelstein \& Hambrick, 1996).

Tenure: For the purpose of this study, tenure is used to reflect the amount of time the principal had been at their school in their current substantive position. The concepts of tenure and age are often viewed together in the perspective of career stages. However, they are two distinct characteristics of the educational leader. The relationship between CEO tenure and organizational performance has interested strategic management researchers for decades (Simsek, 2007). However, the relationship between tenure and performance is much more complex than originally thought (Hambrick \& Fukutomi, 1991). Oplatka (2004) argues that educational leadership theories are not applicable to all stages of a person's career and that the underlying assumptions of different leadership styles (e.g. managerial, participative, transformational, instructional, moral, contingent) are more likely to be appropriate for a particular stage than universal. Numerous models have been proposed to demonstrate the career cycle of educational leaders (Day \& 
Bakioglu, 1996; Ribbins, 1999; Weindling, 1999) all indicating a degree of flexibility and dynamism rather than stability and permanency (Oplatka, 2004). While these studies and models have focused on the career stage, tenure is a similar construct. Drawing from strategy research, Simsek (2007) suggests:

Short-tenured CEOs may lack sufficient awareness to effectively notice and assess strategic risks. They are also unknown, untested and lacking legitimacy, which might limit their performance in execution ... Long-tenured CEOs, however, accumulate a track record, attain a deeper knowledge of the firm's environment, and acquire firm - and job specific - skills. Moreover, a long tenure reflects the extent to which the CEO has been integrated into the networks of key stakeholders and establishes the resources and coalitions that enable the CEO to orchestrate, nurture, and support risky initiatives (p. $654)$.

However, research by Miller \& Shamsie (2001) suggests that long tenure may give rise to risk avoidance and aversion, traditionally referred to as 'maintaining the status quo’. Hambrick and Fukutomi’s (1991) model argues that long tenured managers become committed to their paradigm, avoid information that disconfirms that paradigm, lose interest in their position, and ignore calls for change. These findings are consistent with the 'prospect theory' which has the core idea that people place a higher value on avoiding loss than realizing gain. As with age, the turnover of school leaders in the coming decade makes tenure and the potential fast tracking of future leaders makes tenure an important variable to be investigated. As Hamel and Prahald (1989) warn:

Regardless of ability and effort, fast track managers are unlikely to develop the deep business knowledge they need to discuss technology options, competitors' strategies, and global opportunities substantively. Invariably, therefore, discussions gravitate to 'the numbers', while the value added of managers is limited to the financial and planning savvy they carry from job to job. Knowledge of the company's internal planning and accounting systems, substitutes for substantive knowledge of the business, making competitive innovation unlikely (pp. 74-75). 
Following this discussion, the key research question is whether increased tenure has a positive affect on the mean score for strategic leadership and its sub-scales as measured in this study.

Functional track: Although school leaders are presumed to have a 'generalist perspective', each individual brings his / her job orientation - usually developed from experience in a primary functional area. Hambrick and Mason (1984) proposed that this 'functional track' orientation influences the strategic leadership of top executives. While schools differ from the corporate world, as all school leaders come from teaching ranks (at least at this point in time, as opposed to diverse backgrounds within the organization such as marketing, accounts, human resources), it is the time spent at different levels within the school (e.g. classroom teacher, assistant principal, deputy principals) that is of interest within this analysis. Again, in consideration of the expected turnover of staff, the analysis of the strategic role through the lens of functional track may allow for a differentiation of performance based on time spent at different levels of the hierarchy.

Building on this discussion, the key research question is whether the length of time a person has spent at different levels of the school hierarchy will positively correlate with strategic leadership and its sub-scales as measured in this study.

Throughout the selection of tenure and functional track as variables, primary emphasis has been placed on directly accessible characteristics of educational leaders. In this approach, some important yet complex psychological factors are bypassed. The cognitive bases, values and perceptions of managers are not easy to measure or even 
amenable to direct measurement (Hambrick \& Mason, 1984). However, educational leaders are probably quite reluctant to participate in psychological testing, at least in the sample size required for a meaningful study.

\section{Methods}

Working with the conceptual framework of the paper, the researcher developed the Strategic Leadership Questionnaire (SLQ), consisting of 36 items divided into five scales (consistent with the conceptual framework of the study), each consisting of between six and eight items. To overcome issues relating to self-reporting, participating principals were asked to distribute 12 questionnaires to raters within the school community. Raters could come from four categories, organizationally above the principals (e.g. school education directors), at the same level as the principal (e.g. other principals), organizationally below the principal (e.g. deputy principals, assistant principals, teachers) and other (e.g. administrative staff, parents, school council members). The desired intention was to acquire multiple perspectives on the principal's enactment of their strategic role. Participants were asked to rate the level of performance of the principal (or in the case of the principal, themselves) on a six point Likert scale ranging from 1 'strongly disagree' to 6 'strongly agree'.

Considering the difficulties in acquiring adequate response rates in Australian education systems (Scott, 2003), a single geographic region, the Hunter / Central Coast, within the state of New South Wales was selected as the sample for this study. The Hunter / Central Coast is the largest of the ten school region in the state with 232 primary schools out of a total of 1635 (14.19\%). This enabled initial invitations to be made at 
each district $(n=4)$ principals meeting through a presentation by the researcher and any questions that potential participants had to be answered. It also put a face to the research with the goal of improving the response rate and linked educational leadership research at the local university with the region's schools.

Further criteria were applied to ensure that the sample was appropriate for the research. Removed from the population were relieving principals $(n=35)$ and principals in their first year $(n=28)$, in recognition of the time lag between strategic leadership and management and outcomes (Van de Ven, Angle, \& Poole, 1989). This reduced the total population to 169 principals. Of the 169 principals, 77 returned useable questionnaires (45.56\%). The number of rater questionnaires received was 186. This represents an average return rate of less than three raters per principal (although the range was between zero and ten). In addition to the original invitation, a further two reminders and fortnightly reminders in the regional e-newsletter were used to enhance the return rate.

\section{The Instrument Statistics}

Before moving on to specific statistical analysis to investigate the key research hypotheses, it was important to ascertain whether or not the model behaved appropriately in the study (this process was also undertaken during the trial and pilot study). Initial inquiry focused on undertaking a factor analysis. The Kaiser-Meyer-Olkin measure for sampling adequacy and Bartlett's test for sphericity were used to establish the adequacy of the sample. Both supported the sample size, the KMO value was .86 and Bartlett's test was significant $(p=<.01)$. The next form of analysis was principal component analysis. Having established that the items loaded in a desired manner, scale statistics (responses, 
Table 1. Factor loading and scale statistics from SLQ main study

\begin{tabular}{|c|c|c|c|c|c|c|c|c|c|}
\hline \multirow[b]{2}{*}{ Items } & \multicolumn{5}{|c|}{ Component } & \multicolumn{4}{|c|}{ Scale Statistics } \\
\hline & 1 & 2 & 3 & 4 & 5 & $N$ & $\bar{x}$ & $\sigma$ & $\alpha$ \\
\hline \multicolumn{10}{|l|}{ Envisioning } \\
\hline 8 & .78 & & & & & \multirow{6}{*}{258} & \multirow{6}{*}{4.76} & \multirow{6}{*}{.71} & \multirow{6}{*}{.85} \\
\hline 17 & .78 & & & & & & & & \\
\hline 33 & .77 & & & & & & & & \\
\hline 11 & .76 & & & & & & & & \\
\hline 1 & .75 & & & & & & & & \\
\hline 21 & .72 & & & & & & & & \\
\hline \multicolumn{10}{|l|}{ Engaging } \\
\hline 36 & & .83 & & & & \multirow{8}{*}{258} & \multirow{8}{*}{5.04} & \multirow{8}{*}{.77} & \multirow{8}{*}{.92} \\
\hline 26 & & .83 & & & & & & & \\
\hline 31 & & .82 & & & & & & & \\
\hline 27 & & .80 & & & & & & & \\
\hline 10 & & .78 & & & & & & & \\
\hline 5 & & .77 & & & & & & & \\
\hline 14 & & .77 & & & & & & & \\
\hline 18 & & .74 & & & & & & & \\
\hline \multicolumn{10}{|l|}{ Articulating } \\
\hline 6 & & & .83 & & & \multirow{6}{*}{258} & \multirow{6}{*}{4.92} & \multirow{6}{*}{.67} & \multirow{6}{*}{.81} \\
\hline 32 & & & .81 & & & & & & \\
\hline 3 & & & .77 & & & & & & \\
\hline 13 & & & .68 & & & & & & \\
\hline 24 & & & .66 & & & & & & \\
\hline 20 & & & .57 & & & & & & \\
\hline \multicolumn{10}{|l|}{ Implementing } \\
\hline 23 & & & & .81 & & \multirow{8}{*}{258} & \multirow{8}{*}{4.97} & \multirow{8}{*}{.70} & \\
\hline 4 & & & & .81 & & & & & \\
\hline 16 & & & & .80 & & & & & \\
\hline 28 & & & & .80 & & & & & 91 \\
\hline 34 & & & & .79 & & & & & .91 \\
\hline 12 & & & & .78 & & & & & \\
\hline 7 & & & & .74 & & & & & \\
\hline 30 & & & & .71 & & & & & \\
\hline Monitoring & & & & & & & & & \\
\hline 22 & & & & & .81 & & & & \\
\hline 19 & & & & & .79 & & & & \\
\hline 35 & & & & & .79 & & & & \\
\hline 9 & & & & & .78 & 258 & 48 & 68 & 90 \\
\hline 2 & & & & & .77 & 258 & 4.88 & .68 & .90 \\
\hline 15 & & & & & .75 & & & & \\
\hline 29 & & & & & .74 & & & & \\
\hline 15 & & & & & .70 & & & & \\
\hline Eigenvalues & 3.45 & 5.03 & 3.15 & 4.86 & 4.69 & & & & \\
\hline $\mathrm{R}^{2}$ & 57.55 & 62.85 & 52.42 & 61.07 & 58.62 & & & & \\
\hline
\end{tabular}

Extraction method: principal component analysis 
mean, and standard deviation) were calculated. In addition, Cronbach's alpha coefficient was used to measure the reliability of the scales. The alpha coefficient ranged from .81 to .92 , which as cited previously, is appropriate for research in the social sciences (DeVillis, 2003). Table 1 shows the factor loading and scale statistics based on the main study responses.

\section{Results}

The purpose of this study was to empirically investigate the strategic role of the public primary school principal in relation to the leader characteristics of tenure and functional track.

Tenure: Due to the disparity in time spent at various levels of the school hierarchy, the measure of tenure was divided into four categories: less than three years; four to six years; seven to ten years; and greater than 11 years. The mean score rose over the first two categories before dropping away in the third (see Table 2). Although an interesting trend was that the mean rose again in the fourth category to its highest point.

Excluding the phenomenon of the fourth category for the moment, the fluctuation of the mean is consistent with the work of Earley and Weindling (2007) who proposed that principal first take hold (year one), reshape (year two) and refine (years three to four) before consolidating (years five to seven) and then reaching a plateau (years eight onwards). An alternative perspective is that of Oplatka (2004) who discusses the principal career stages as 'induction', 'establishment', 'maintenance vs renewal' and then 
finally 'disenhancement'. Both models propose that performance reaches either a plateau or decline at the end, whereas the data in this study portrays a different situation.

Whereas during early stages of tenure a principal is socialized into the school and their new role (both at the school and systemic level), it is possible that over time the pattern of leadership behavior exercised by the principal becomes part of the school as an organization and it is accepted as the norm rather than the exception. As seven years provides the opportunity for a generation of students to move from kindergarten through to leaving primary school, staying longer than 11 years socializes a generation of parents to the principal's style of leadership, take on the situation, and context of the school. Assuming that a principal would not stay in a working environment where they are not well received by staff, students or the community, a long serving principal may lead a school towards a single governing paradigm.

Prior to moving into a position, a leader's governing paradigm (made up of his / her pre-existing knowledge system and repertoire of leadership and management tools) is already established. He or she may have previously held a series of assistant or deputy principal positions, acting / relieving principal positions or possibly served as a principal in a smaller school. By virtue of being promoted, a principal is correct in assuming that their personal paradigm has potential and is appropriate for their new posting, or at least better than those of other applicants. 
Table 2. Scale scores by tenure

\begin{tabular}{|c|c|c|c|c|c|c|c|c|}
\hline Scale & $n$ & $\bar{x}$ & $\sigma$ & $\mathrm{F}$ & $d f$ & $p$ & $f$ & $\omega^{2}$ \\
\hline Envisic & & & & \multirow{6}{*}{2.43} & \multirow{6}{*}{71} & \multirow{6}{*}{.06} & \multirow{6}{*}{.37 } & \\
\hline$-\leq 3$ & 22 & 4.68 & .52 & & & & & \multirow{4}{*}{.07} \\
\hline$-4-6$ & 24 & 4.83 & .41 & & & & & \\
\hline - 7-10 & 17 & 4.48 & .58 & & & & & \\
\hline$-11+$ & 10 & 5.01 & .38 & & & & & \\
\hline Engagi & & & & & & & & \\
\hline$-\leq 3$ & 22 & 5.14 & .50 & \multirow{5}{*}{2.42} & \multirow{5}{*}{71} & \multirow{5}{*}{.06} & \multirow{5}{*}{.37} & \multirow{4}{*}{.07} \\
\hline$-4-6$ & 24 & 5.19 & .43 & & & & & \\
\hline - 7-10 & 17 & 4.74 & .64 & & & & & \\
\hline$-11+$ & 10 & 5.25 & .44 & & & & & \\
\hline Articul & & & & & & & & \\
\hline$-\leq 3$ & 22 & 4.86 & .52 & \multirow{5}{*}{1.51} & \multirow{5}{*}{71} & \multirow{5}{*}{.21} & \multirow{4}{*}{.29} & \multirow{4}{*}{.03} \\
\hline$-4-6$ & 24 & 4.97 & .42 & & & & & \\
\hline$-7-10$ & 17 & 4.69 & .58 & & & & & \\
\hline$-11+$ & 10 & 5.12 & .28 & & & & & \\
\hline Implen & & & & & & & & \\
\hline$-\leq 3$ & 22 & 5.02 & .44 & \multirow{5}{*}{1.48} & \multirow{5}{*}{71} & \multirow{5}{*}{.22} & \multirow{5}{*}{.29} & \multirow{5}{*}{.02} \\
\hline$-4-6$ & 24 & 5.05 & .39 & & & & & \\
\hline - 7-10 & 17 & 4.74 & .55 & & & & & \\
\hline$-11+$ & 10 & 5.09 & .36 & & & & & \\
\hline Monitc & & & & & & & & \\
\hline$-\leq 3$ & 22 & 4.86 & .45 & \multirow{4}{*}{1.85} & \multirow{4}{*}{71} & \multirow{5}{*}{.13 } & \multirow{4}{*}{.32} & \multirow{4}{*}{.04} \\
\hline$-4-6$ & 24 & 4.94 & .42 & & & & & \\
\hline$-7-10$ & 17 & 4.68 & .48 & & & & & \\
\hline$-11+$ & 10 & 5.11 & .39 & & & & & \\
\hline Overal & & & & & & & & \\
\hline$-\leq 3$ & 22 & 4.93 & .44 & \multirow{4}{*}{2.10} & \multirow{4}{*}{71} & \multirow{4}{*}{.09} & \multirow{4}{*}{.34} & \\
\hline - 4-6 & 24 & 5.01 & . .37 & & & & & 06 \\
\hline - 7-10 & 17 & 4.68 & .53 & & & & & \\
\hline$-11+$ & 10 & 5.12 & .35 & & & & & \\
\hline
\end{tabular}

In a personal correspondence cited in Earley and Weindling (2007), Pam

Sammons, one of the authors of Mortimore et al. (1988) was cited as saying:

We found long serving (primary) headteachers were associated with less effective schools - of course this does not mean all schools with long serving headteachers were less effective, it was a trend across our sample. Long serving headteachers were those with 11 or more years in the same post. We also found new headteachers (first three years) were generally less effective. Mid term headteachers were associated with most effective schools (three to seven years in the post). 
With long serving headteachers the task is different and the implication for LEAs (and governing bodies) is that they need to find ways of supporting those headteachers and if possible of rekindling their energy and enthusiasm. In this situation many school boards in the US or Canada would simply transfer heads from one school to another. In England, where headteachers have tenure within their schools, this is not possible (p. 81).

The findings of this study contradict what has been found in previous work and although their existed no statistically significant difference and the omega squared size ranged from 2.4 to 7.0 percent of the variance, it does raise the question of tenure and its effect on practice.

Functional track: The previously unexplored, in the educational leadership literature, construct of functional track required a somewhat different form of analysis from the earlier demographic variables. Rather than attempting to break the length of time at each stage of the organizational hierarchy into categories for an analysis of variance, as the artificially produced categories would dilute reality to such a point that the data would become redundant, a Pearson product-moment-coefficients correlation was completed (see Table 3). Two streams from the analysis are of particular interest, the first being the negative correlation of teaching and time spent as a medium sized school principal to each dimension of the strategic role model, and secondly the presence of statistically significant correlations. 
Table 3. Pearson product-moment coefficients of correlations between means for scales and the principal's career path

\begin{tabular}{|c|c|c|c|c|c|c|}
\hline & Envisioning & Engaging & Articulating & Implementing & Monitoring & Overall \\
\hline $\begin{array}{l}\text { Classroom } \\
\text { teacher }\end{array}$ & -.05 & -.07 & -.09 & -.08 & -.06 & -.08 \\
\hline Sig. & .70 & .58 & .51 & .57 & .63 & .56 \\
\hline$N$ & 59 & 59 & 59 & 59 & 59 & 59 \\
\hline \multicolumn{7}{|l|}{ Assistant } \\
\hline Principal & .02 & .16 & .16 & .13 & .13 & .13 \\
\hline Sig. & .89 & .21 & .22 & .30 & .30 & .30 \\
\hline$N$ & 61 & 61 & 61 & 61 & 61 & 61 \\
\hline \multicolumn{7}{|l|}{ Deputy } \\
\hline Principal & .09 & .10 & .07 & .16 & .17 & .13 \\
\hline Sig. & .49 & .46 & .57 & .22 & .19 & .32 \\
\hline$N$ & 61 & 61 & 61 & 61 & 61 & 61 \\
\hline \multicolumn{7}{|l|}{ Small } \\
\hline Principal & .29 & .16 & .13 & .05 & .26 & .20 \\
\hline Sig. & .02 & .21 & .33 & .69 & .05 & .13 \\
\hline$N$ & 62 & 62 & 62 & 62 & 62 & 62 \\
\hline \multicolumn{7}{|l|}{ Medium } \\
\hline Principal & -.28 & -.22 & -.17 & -.26 & -.19 & -.25 \\
\hline Sig. & .03 & .09 & .20 & .04 & .15 & .06 \\
\hline$N$ & 61 & 61 & 61 & 61 & 61 & 61 \\
\hline \multicolumn{7}{|l|}{ Large } \\
\hline Principal & .10 & .06 & .14 & .16 & .09 & .12 \\
\hline Sig. & .47 & .64 & .30 & .23 & .52 & .38 \\
\hline$N$. & 61 & 61 & 61 & 61 & 61 & 61 \\
\hline \multicolumn{7}{|l|}{ Non school } \\
\hline Sig. & .40 & .68 & .35 & .48 & .35 & .41 \\
\hline$N$ & 62 & 62 & 62 & 62 & 62 & 62 \\
\hline
\end{tabular}

Note: Statistically significant correlations at the $\mathrm{p}=<.05$ are indicated in bold.

In contrast to the notion that extended experience in the classroom is needed to lead a school (and this argument could be extended to include a school system), the data presents a situation where, at least in this sample, time in the classroom is negatively correlated with the enactment of the strategic role. At least a further two views could 
taken to this data. First, this pattern could be read in such a way to support the idea that strategic leadership and management are so poorly matched to the educational environment that those who spend considerable time working in the profession are somewhat removed from the entire role. Alternatively, it could be argued that spending considerable time in the classroom reduces the understanding and scope of education beyond the classroom therefore reducing the enactment of the strategic role.

\section{Conclusion}

This paper set out to investigate the extent to which public primary school principals exhibit strategic leadership and management as described by a model derived from the knowledge base on the topic from the literature in the field. Having established that the proposed model was evidenced in a consistent manner and that the designed instrument behaved in an appropriate fashion, it is concluded that both tenure and functional track matter in relation to school leadership, and particularly the strategic dimension. While it is noted that Heck and Hallinger (2005) consider the study of leaders traits and demographics to be of personal interest to the researcher, but of limited value to the field at large, and more importantly, demonstrating a weak connection to the general literature in the field, the strategic role was explored through demographic conditions as a potential moderating factor on the enactment of the role. There is sufficient evidence in this study to propose the possibility that the demographic variables of tenure and functional track, both crucial factors in the contemporary and immediate future staffing contexts of many western education systems, have a moderating effect on the enactment of the strategic role of principals. Of course any such findings and conclusions are open to critique and 
further testing in the aim of theory development and this is where to end this paper. The challenge rests now with the reader to either extend, refute, or hopefully at the very least, engage in discussion about the impact of tenure and functional track on education systems, and more importantly, individual schools as we prepare to embrace the challenges of finding the next generation of school leaders.

\section{References}

Davies, B. J., \& Davies, B. (2006). Developing a model for strategic leadership in schools. Educational Management Administration \& Leadership, 34(1), 121-139.

Day, C., \& Bakioglu, A. (1996). Development and disenchantment in the professional lives of headteachers. In I. Goodson \& A. Hargreaves (Eds.), Teachers professional lives (pp. 123-139). London: Falmer Press.

DeVillis, R. F. (2003). Scale development: theory and applications (2nd ed. Vol. 26). London: SAGE.

Eacott, S. (2004). Leading towards excellence: a model for implementing effective school-wide change. The Practising Administrator, 26(3), 7-9.

Eacott, S. (2006a). Strategy in schools: from direction to plan. The Australian Educational Leader, 28(2), 24-26.

Eacott, S. (2006b). Strategy: an educational leadership imperative. Perspectives on educational leadership, 16(6), 1-2.

Eacott, S. (2007a). Demographic proxies, strategy and educational leadership. Paper presented at the NSW Institute for Educational Research Annual Conference.

Eacott, S. (2007b, 29 July - 1 August). Strategy and the practising educational leader. Paper presented at the Directions for Catholic educational leadership in the 21st century: the vision, challenges and reality, Sydney.

Eacott, S. (2007c). Strategy and the school principal. Journal of Catholic School Studies, 79(2), 3-18.

Eacott, S. (2008a). An analysis of contemporary literature on strategy in education. International Journal of Leadership in Education, 11(3), 257-280.

Eacott, S. (2008b). Strategy and educational leadership: In search of unity. Journal of Educational Administration, 46(3), 353-375.

Eacott, S. (2008c). Strategy and the principal. Unpublished PhD, The University of Newcastle, Australia.

Earley, P., \& Weindling, D. (2007). Do school leaders have a shelf life? Career stages and headteacher performance. Educational Management Administration \& Leadership, 35(1), 73-88.

Finkelstein, S., \& Hambrick, D. (1996). Strategic leadership: top executives and their effects on organizations. St. Paul/Minneapolis: West Publishing. 
Hambrick, D., \& Fukutomi, G. (1991). The seasons of a CEO's tenure. Academy of Management Review, 16(4), 719-742.

Hambrick, D., \& Mason, P. (1984). Upper echelons: the organization as a reflection of its top managers. Academy of Management Review, 9(2), 195-206.

Hamel, G., \& Prahalad, C. K. (1989). Strategic intent. Harvard Business Review, 67(3), 63-76.

Heck, R. H., \& Hallinger, P. (2005). The study of educational leadership and management: where does the field stand today? Educational Management Administration \& Leadership, 33(2), 229-244.

Miller, D., \& Shamsie, J. (2001). Learning across the life cycle: experimentation and performance among Hollywood studio heads. Strategic Management Journal, 22(8), 725-745.

Mortimore, P., Sammons, P., Stoll, L., Lewis, D., \& Ecob, R. (1988). School matters: the junior years. Wells, Somerset: Open Books.

Oplatka, I. (2004). The principal's career stage: an absent element in leadership perspectives. International Journal of Leadership in Education, 7(1), 43-55.

Ribbins, P. (1999). Understanding leadership: developing headteachers. In T. Bush, L. Bell, R. Bolam, R. Glatter \& P. Ribbins (Eds.), Educational management: redefining theory, policy and practice (pp. 77-89). London: Paul Chapman.

Scott, G. (2003). Learning principals: leadership capability and learning research in New South Wales Department of Education and Training. Sydney: New South Wales Department of Education and Training.

Simsek, Z. (2007). CEO tenure and organizational performance: an intervening model. Strategic Management Journal, 28, 653-662.

Van de Ven, A. H., Angle, H. L., \& Poole, M. S. (1989). Research in the management of innovation: the Minnesota studies. New York: Harper \& Row.

Weindling, D. (1999). Stages in headship. In T. Bush, L. Bell, R. Bolam, R. Glatter \& P. Ribbins (Eds.), Educational management: redefining theory, policy and practice (pp. 90-101). London: Paul Chapman. 